Dhaka Univ. J. Biol. Sci. 27(2): 135-144, 2018 (July)

\title{
LARVICIDAL EFFICACY OF THE CRUDE LEAF EXTRACTS OF EUCALYPTUS CAMALDULENSIS DEHN (MYRTALES: MYRTACEAE) AGAINST THE MOSQUITO LARVAE OF CULEX QUINQUEFASCIATUS SAY (DIPTERA: CULICIDAE)
}

\author{
Humayun Reza Khan*, Nigar Sultana and Prova Sharmin \\ Department of Zoology, University of Dhaka, Dhaka-1000, Bangladesh
}

Key words: Eucalyptus camaldulensis, Cx. quinquefasciatus, Larvicidal efficacy

\begin{abstract}
Eucalyptus camaldulensis was assayed to evaluate the larvicidal efficacy of its leaf extracts against the $3^{\text {rd }}$ instar larvae of Culex quinquefasciatus at five dose concentrations (viz. 0.25, 0.50, 0.75, 1.0, 1.25, 1.5, 2.0, 2.5 and 3.0) in five solvents (viz. chloroform, ethanol, di-chloromethane, acetone and water) based extracts after $24 \mathrm{hrs}$ exposure. Among all the extracts the shade dried chloroform based leaf extracts showed the highest larvicidal efficacy (viz. 42.67, 56.67, 68.0, 92.67 and $100 \%$ ) at low dose concentrations of $0.25,0.50,0.75,1.0$ and 1.25, respectively while the sun dried water based leaf extracts showed the lowest larvicidal efficacy (viz. 21.33, 30.67, 48.67, 58.0 and 74.0\%) at high dose concentrations of 1.0, 1.5, 2.0, 2.5 and 3.0, respectively among the ten different experimental conditions. The relative potency of ten types of crude leaf extracts of E. camaldulensis against the mosquito larvae are shown as follows in decreasing order on the basis of $\mathrm{LC}_{50}$ value : Shade dried chloroform based leaf extract $(0.356 \mathrm{mg} / \mathrm{ml})>$ sun dried chloroform based leaf extract $(0.400 \mathrm{mg} / \mathrm{ml})>$ shade dried di-chloromethane based leaf extract $(0.411 \mathrm{mg} / \mathrm{ml})>$ sun dried dichloromethane based leaf extract $(0.579 \mathrm{mg} / \mathrm{ml})>$ shade dried ethanol based leaf extract $(0.736 \mathrm{mg} / \mathrm{ml})>$ sun dried ethanol based leaf extract $(0.817 \mathrm{mg} / \mathrm{ml})>$ shade dried acetone based leaf extract $(1.000 \mathrm{mg} / \mathrm{ml})>$ sun dried acetone based leaf extract $(1.251 \mathrm{mg} / \mathrm{ml})>$ shade dried water based leaf extract $(1.807 \mathrm{mg} / \mathrm{ml})>$ Sun dried water based leaf extract $(2.020 \mathrm{mg} / \mathrm{ml})$. The effectiveness of the shade dried leaf extracts was shown higher than the sun dried leaf extracts under comparable condition. No mortality was observed in control treatment. The study revealed that these leaf extracts have the potency to consider as an effective larvicidal agent. It is an alternative source for developing a novel larvicide for controlling the mosquito species.
\end{abstract}

\section{Introduction}

Mosquito spreads various vector borne diseases, such as malaria which remains an important cause of morbidity and mortality, particularly in the Chittagong Hill tracts and in the border belt areas ${ }^{(1)}$. Lymphatic filariasis continues to be a problem, despite multiple rounds of mass drug administration(2). Dengue, Japanese encephalitis and Chikungunya

*Author for correspondence: <humreza@yahoo.com>. 
viruses are also transmitted by mosquitoes in Bangladesh ${ }^{(3)}$. There are 123 species of Culicidae found in Bangladesh, among them 33 species belong to the genus Culex(4). The predominant mosquito species in Dhaka city is Cx. quinquefasciatus ${ }^{(5)}$.

Plants are considered as largely complicated chemical factories which can turn the relatively simple ingredients of air and water into so many compounds including liquids and oils (6). Eucalyptus camaldulensis, tree is under the genus Eucalyptus. There is a specific compound like essential oil of Eucalyptus in the different parts of this genus(7). It is a complex mixture of mainly terpenoids, particularly monoterpenes $\left(\mathrm{C}_{10}\right)$ and sesquiterpenes $\left(\mathrm{C}_{15}\right)$ and various aromatic phenols, oxides, ethers, alcohols, esters, aldehydes and ketones ${ }^{(8-9)}$. Among the various components eucalyptus oil, 1, 8 cineole $\left(\mathrm{C}_{10} \mathrm{H}_{18} \mathrm{O}\right)$ is the most important one and is largely responsible for a variety of its pesticidal properties ${ }^{(10)}$.

Eucalyptol is a significant monoterpene because of having antimicrobial(11) and antifungal effects. Over 2000 plants are known to have phytochemicals that are capable of killing or repelling mosquitoes(12). Eucalyptus camaldulensis is one of those plants that possess some of these phytochemicals and claimed to possess pesticidal and also medicinal activities on various ailments. Various biological properties have been attributed to the genus Eucalyptus, among them larvicidal activity on culicids(13), insecticidal activity against beetles ${ }^{(14)}$, and repellent action against Phlebotomus papatasi(15). Essential oil, whole plant extract, aqueous extract, leaf extract, acetone extract, ethanolic extract, methanol extract of different plants were used against mosquitoes as adulticide, larvicide, growth regulator, repellent, anti-popuational and oviposition inhibitor worldwide. The leaf essential oil from E. camaldulensis tested against matured and immatured mosquito vector An. stephensi showed an excellent inhibitory effect, and $100 \%$ mortality was observed at $0.16 \mathrm{mg} / \mathrm{ml}^{(16)}$. There were several reports on the repellency of Eucalyptus plants against mosquitoes ${ }^{(17)}$. The objective of the present study was to evaluate the larvicidal and residual effects of the crude leaf extracts of E. camaldulensis against the 3rd instar larvae of $C x$. quinquefasciatus mosquito with a view to assuring the safety of plant-based insecticides as well as promising new developments in the field.

\section{Materials and Methods}

The entire research work that included the collection of the larvae of $C x$. quinquefasciatus, rearing of mosquito $C x$. quinquefasciatus, collection of plant (E. camaldulensis) parts, extraction procedure, dose preparation, bioassay test and statistical analysis were conducted at the Zoological Garden of Dhaka University, Entomological Research Laboratory of the Department of Zoology of the University of Dhaka and the Center for Advanced Research in Sciences (CARS), University of Dhaka. This research work was conducted from March, 2016 to July, 2017. 
Preparation of plant extracts: To prepare plant extract, the leaves of the E. camaldulensis were collected from Shahidullah Hall premises, Curzon Hall in Dhaka University. The leaves of E. camaldulensis were collected in fresh condition, then all the leaves were divided into two portions one was of sun dried and the other one was of shade dried. The leaf samples were subjected to grind with the help of an electric grinder machine to make the leaves into powdered form. The powder was stored in an air tight container for subjecting to the next step of experiments.

Ten conical flasks $(500 \mathrm{ml})$ were taken, of which five were considered for sun dried sample preparation and the rest five for shade dried. These conical flasks were initially washed with distilled water for the preparation of the sample solutions. Fifty grams of each of the sun or shade dried leaf powders were measured with a weight machine and mixed with $300 \mathrm{ml}$ of $98 \%$ ethanol, $99 \%$ chloroform, $99 \%$ acetone, $99.8 \%$ di-chloroform or water separately in different conical flasks. At first the powder and any of the solvents were mixed by hand shaking and then kept for $24 \mathrm{hrs}$ with periodic shaking in an orbital shaker machine (R 100 LUCKHAM) at $100 \mathrm{rpm}$ and $32^{\circ} \mathrm{C}$ temperature. The mouth of the conical flasks was wrapped with aluminum foil paper for avoiding contamination of the environment. After $24 \mathrm{hrs}$ shaking, the solutions were filtered by funnel through cotton filtration. The filtrates were collected in another conical flask. This procedure was repeated for three times by adding fresh volume of respective solvents each time. The total volume of the sample was concentrated separately in a rotary evaporator machine. For organic extraction, all of the solutions were evaporated at $80 \mathrm{rpm}$ and $50^{\circ} \mathrm{C}$ temperature and for aqueous solution evaporation temperature was $60^{\circ} \mathrm{C}$. After evaporation the samples were found in dried or pest condition which were collected with the help of a spatula and then stored in an air tight jar at $4^{\circ} \mathrm{C}$ in a refrigerator for further uses. These extracts were used for dose preparation.

Mosquito rearing: The mosquito larvae of $C x$. quinquefasciatus (Say) were collected from their natural breeding habitats near the Dhaka University campus. The larvae along with the drain water were brought to the laboratory. The identification of the larvae of $C x$. quinquefasciatus was confirmed following the standard method ${ }^{(18)}$. The temperature and relative humidity of the ambient environment of the laboratory during larval rearing process were maintained at $34 \pm 2^{\circ} \mathrm{C}$ and $75-85 \%$, respectively. The larvae were reared in a Petri dish containing tap water. They were provided routinely with baby food powder (Cerelac, Nestle, Bangladesh Ltd.) and yeast powder as their food up to pupation stage. The pupae were separated from the larvae which were then kept into an adult rearing cage for the emergence of adult mosquito. The adult rearing cage was constructed with a thin iron rod frame (size: $30 \times 30 \times 30 \mathrm{~cm}$ ). The iron frame was covered with a piece of mosquito net except an opening at one side fixed with a long sleeve of mosquito net through which necessary equipment were taken in and out except adult mosquitoes. This sleeve was tied when it was not in use. The basal part of the cage was made up of a 
wooden plate. Adult mosquitoes were emerged within two to three days of pupation. The adults were provided with $10 \%$ glucose solution as their food. The glucose solution soaked in a cotton ball was placed in a Petri dish inside the rearing cage. The male mosquito only feed on glucose solution throughout their life time, but in case of female mosquito they took glucose solution for the first two to three days of emergence then they required blood meal as it is essential for their egg development. The source of blood meal in the laboratory condition was a pegion, Columba livia. The pigeon was kept inside the rearing cage for two or three hours during of which the female mosquitoes sucked blood. A well fed female abdomen was swollen and became red in color which gradually turned into dark red. When the eggs started developing the female mosquito became greyish in color. At this stage the female mosquito is called gravid female. In a few days when its blood meal was fully digested its abdomen became dark black in color. A jar containing tap water kept inside the rearing cage for oviposition of the gravid female mosquito. Oviposition took place within three days after blood meal. Immediately after laying, boat shaped off white color egg rafts were floating on the surface of the water which turned chocolate color with the time passed by. Each egg raft contained $80-120$ eggs. The eggs hatched into 1st instar larvae within two days. Gradually the 1st instars larvae moulted into 2nd, 3rd and 4th instar larvae. These larvae were identified with a magnifying lens. The larvae were fed continuously and the late 4th instar larvae gradually moulted into pupae and then adult form. Thus the rearing procedure was continued throughout the experimental time and several generations of mosquito populations were established which provided a continuous supply of 3rd instar larvae as test larvae.

Dose preparation: As the organic solvents based leaf extracts were insoluble in water, di-methyl sulfoxide (DMSO) was used to make the concentrated solvent water soluble ${ }^{(19)}$. Thus, a series of different concentrations, such as 25, 50,75, 100 and $125 \mathrm{mg}$ of extracts per $100 \mathrm{ml}$ of distilled water each were prepared with chloroform and di-chloromethane organic extracts. On the other hand 50, 100, 150, 200 and $250 \mathrm{mg}$ of extracts per $100 \mathrm{ml}$ of water were prepared with acetone or ethanol based organic extracts. For aqueous extracts 100, 150, 200, 250 and $300 \mathrm{mg}$ doses were prepared. At each dose $2 \mathrm{ml}$ DMSO was added to make the organic solvent based extracts water soluble. The concentration of the respective doses of chloroform and di-chloromethane based organic extracts were 0.25 , $0.5,0.75,1.0$ and $1.25 \mathrm{mg} / \mathrm{ml}$. The concentrations of the respective doses of acetone and ethanol based organic extracts were $0.5,1.0,1.5,2$ and $2.5 \mathrm{mg} / \mathrm{ml}$. In case of aqueous extracts the concentration of the respective doses was 1.0, 1.5, 2.0, 2.5 and $3.0 \mathrm{mg} / \mathrm{ml}$. The prepared doses were applied against the 3rd instars larvae of $C x$. quinquefasciatus for bioassay test.

Bioassay test: In this experiment a larvicidal bioassay method was followed with slight modifications ${ }^{(20)}$. For bioassay studies, 50 larvae of 3 rd instar were introduced into 
$250 \mathrm{ml}$ of glass beaker containing $100 \mathrm{ml}$ of tap water and various concentrations of the extract preparations were added according to above description. The flasks were kept at room temperature $\left(32 \pm 2^{\circ} \mathrm{C}\right), 80 \pm 5 \%$ of relative humidity and 13L: 11D (photoperiod). The death of the larvae was recorded after 24 hours of exposure and the moribund larvae were counted as dead. A set of control using 2.0\% DMSO as control 1 and an untreated set of larvae containing tap water were also run for the observation of larval death in case of DMSO and tap water. These two sets of control were run for correcting the mortality. The toxicity of the extracts was calculated as $\mathrm{LC}_{50}$ and $\mathrm{LC}_{90}$ values representing 50 and $90 \%$ of the test larvae died, respectively. Both $\mathrm{LC}_{50}$ and $\mathrm{LC}_{90}$ values were calculated for 24 hours of exposure.

The number of the larvae died at each dose concentration was recorded and the mortality percentage values were calculated by using the formula:

Percentage of mortality $=\frac{\text { No. of larvae died }}{\text { No. of tested larvae }} \times 100$

When the mortality in control was more than $5 \%$, the percentage mortality was corrected by using Abbott's (1925) formula:

Corrected mortality $=\frac{\text { Larval mortality in treatment }- \text { Larval mortality in control }}{100-\text { Control mortality }} \times 100$

Statistical analysis: Larval death rate was observed and corrected mortality was obtained by applying Abbott's formula (21). Fifty per cent lethal concentration (LC50) and 90\% lethal concentration (LC90) and at 95\% confidence intervals of lower and upper confidence limits were determined by parameter estimation. Other statistical analysis like One-way ANOVA and Post Hoc Test (Bonferroni) for multiple comparison between different dose concentrations were calculated by using IBM SPSS statistics 20 (Statistical Package of Social Science) software; here significance level was set at $\mathrm{p}<0.05$.

\section{Results and Discussion}

The present study of the plant extracts from Eucalyptus camaldulensis demonstrates the presence of larvicidal toxic potentiality of E. camaldulensis. Table 1 represented the mean mortality rate of the $3 \mathrm{rd}$ instar larvae of $C x$. quinquefasciatus exposed to $24 \mathrm{hrs}$ at different doses of sun and shade dried chloroform or di-chloromethane based leaf extracts of $E$. camaldulensis. Here, $100 \%$ of larval mortality was found at $1.25 \mathrm{mg} / \mathrm{ml}$ dose concentration of shade dried chloroform based leaf extract. Whereas, at the same dose concentration, both chloroform sun and di-chloromethane shade extracts showed almost equal percentage of mortality 93.33 and 94.67 , respectively. Comparing the effects of other extracts showed lesser activity. 
Table 1. Mean mortality rate of the 3rd instar (50) larvae of Cx. quinquefasciatus at different doses of sun and shade dried chloroform and di-chloromethane based leaf extracts of $E$. camaldulensis. Values are mean of three replicates.

\begin{tabular}{lccccc}
\hline \multirow{2}{*}{ Extracts } & \multicolumn{5}{c}{ Larval mortality at different dose concentrations (Mean\% \pm Sd) } \\
\cline { 2 - 6 } & $0.25 \mathrm{mg} / \mathrm{ml}$ & $0.50 \mathrm{mg} / \mathrm{ml}$ & $0.75 \mathrm{mg} / \mathrm{ml}$ & $1.0 \mathrm{mg} / \mathrm{ml}$ & $1.25 \mathrm{mg} / \mathrm{ml}$ \\
\hline $\begin{array}{l}\text { Chloroform } \\
\text { Sun dried) }\end{array}$ & $37.33 \pm 22.89$ & $52.0 \pm 31.89$ & $66.67 \pm 40.39$ & $86.00 \pm 52.69$ & $93.33 \pm 57.15$ \\
$\begin{array}{l}\text { Chloroform } \\
\text { (Shade dried) }\end{array}$ & $42.67 \pm 26.18$ & $56.67 \pm 34.71$ & $68.00 \pm 41.73$ & $92.67 \pm 56.76$ & $100.00 \pm 61.23$ \\
$\begin{array}{l}\text { Di-chloromehane } \\
\text { (Sun dried) }\end{array}$ & $28.67 \pm 17.59$ & $42.0 \pm 25.74$ & $51.33 \pm 31.47$ & $62.67 \pm 38.39$ & $84.0 \pm 51.48$ \\
$\begin{array}{l}\text { Di-chloromethane } \\
\text { (Shade dried) }\end{array}$ & $37.33 \pm 22.91$ & $46.67 \pm 28.66$ & $70.0 \pm 42.88$ & $84.0 \pm 51.45$ & $94.67 \pm 59.24$ \\
\hline
\end{tabular}

Mean mortality rate of the 3rd instar larvae of $C x$. quinquefasciatus exposed to $24 \mathrm{hrs}$ at different doses of sun and shade dried ethanol and acetone based leaf extracts of $E$. camaldulensis were represented in Table 2 . At $2.5 \mathrm{mg} / \mathrm{ml}$ dose concentration of ethanol based shade dried leaf extract, $100 \%$ of the tested larvae were died where at the same dose of sun dried extracts $95.33 \%$ of the larvae were killed. Other extract preparations and doses showed less effectivity against the larvae.

Table 2. Mean mortality rate of the 3rd instar (50) larvae of Cx. quinquefasciatus at different doses of sun and shade dried ethanol and acetone based leaf extracts of E. camaldulensis. Values are mean of three replicates.

\begin{tabular}{lccccc}
\hline Extracts & \multicolumn{5}{c}{ Larval mortality at different dose concentrations (Mean\% \pm Sd) } \\
\cline { 2 - 6 } & $0.5 \mathrm{mg} / \mathrm{ml}$ & $1.0 \mathrm{mg} / \mathrm{ml}$ & $1.5 \mathrm{mg} / \mathrm{ml}$ & $2.0 \mathrm{mg} / \mathrm{ml}$ & $2.5 \mathrm{mg} / \mathrm{ml}$ \\
\hline $\begin{array}{l}\text { Ethanol } \\
\text { (Sun dried) }\end{array}$ & $26.67 \pm 16.41$ & $62.67 \pm 38.41$ & $75.33 \pm 46.13$ & $84.0 \pm 51.45$ & $95.33 \pm 58.38$ \\
$\begin{array}{l}\text { Ethanol } \\
\text { (Shade dried) }\end{array}$ & $29.33 \pm 17.97$ & $70.67 \pm 43.28$ & $78.67 \pm 48.19$ & $90.00 \pm 55.12$ & $100.00 \pm 61.23$ \\
$\begin{array}{l}\text { Acetone Sun } \\
\text { dried) }\end{array}$ & $21.33 \pm 13.11$ & $41.33 \pm 25.31$ & $54.00 \pm 33.08$ & $64.00 \pm 39.20$ & $78.00 \pm 47.78$ \\
$\begin{array}{l}\text { Acetone } \\
\text { (Shade dried) }\end{array}$ & $25.33 \pm 15.52$ & $48.00 \pm 29.41$ & $64.00 \pm 39.28$ & $77.33 \pm 47.36$ & $84.00 \pm 51.44$ \\
\hline
\end{tabular}

Table 3 depicted the mean mortality rate of the 3rd instar larvae of $C x$. quinquefasciatus exposed to $24 \mathrm{hrs}$ on the basis of different doses of sun and shade dried aqueous leaf extracts of E. camaldulensis. Here, the highest mortality (74.00 and 84.67\%) 
and the lowest mortality (21.33 and $24.67 \%$ ) were found at $3.0 \mathrm{mg} / \mathrm{ml}$ and $1.0 \mathrm{mg} / \mathrm{ml}$ dose concentration, respectively.

Table 3. Mean mortality rate of the 3rd instar (50) larvae of $C x$. quinquefasciatus at different doses of sun and shade dried water based leaf extracts of E. camaldulensis. Values are mean of three replicates.

\begin{tabular}{lccccc}
\hline \multirow{2}{*}{ Extracts } & \multicolumn{5}{c}{ Larval mortality at different dose concentrations (Mean\% \pm Sd) } \\
\cline { 2 - 6 } & $1.0 \mathrm{mg} / \mathrm{ml}$ & $1.5 \mathrm{mg} / \mathrm{ml}$ & $2.0 \mathrm{mg} / \mathrm{ml}$ & $2.5 \mathrm{mg} / \mathrm{ml}$ & $3.0 \mathrm{mg} / \mathrm{ml}$ \\
\hline Water & $21.33 \pm 13.11$ & $30.67 \pm 18.85$ & $48.67 \pm 29.81$ & $58.00 \pm 35.64$ & $74.00 \pm 45.33$ \\
(Sun dried) & & & & & \\
Water & $24.67 \pm 15.17$ & $36.67 \pm 22.51$ & $49.33 \pm 30.28$ & $63.33 \pm 38.90$ & $84.67 \pm 51.91$ \\
(Shade dried) & & & & & \\
Water + DMSO & $0.0 \pm 0.0$ & $0.0 \pm 0.0$ & $0.0 \pm 0.0$ & $0.0 \pm 0.0$ & $0.0 \pm 0.0$ \\
\hline
\end{tabular}

In this experiment, the effect of various extracts was studied in a dose dependent manner. It was shown that when dose concentrations were increased, larval mortality were also increased in the same manner. The larvicidal efficacy of the crude leaf extracts of E. camaldulensis against 3rd instar larvae of $C x$. quinquefasciatus was shown in Table 4. All the extracts showed higher larvicidal efficacy against the Culex larvae. Among all the extracts, the shade dried chloroform based leaf extracts showed the highest (LC50 0.356 $\mathrm{mg} / \mathrm{ml}$ ) larvicidal efficacy at low $1.25 \mathrm{mg} / \mathrm{ml}$ dose concentration and the sun dried water based leaf extracts showed the lowest (LC50 $2.020 \mathrm{mg} / \mathrm{ml}$ ) larvicidal efficacy at high 3.0 $\mathrm{mg} / \mathrm{ml}$ dose concentration. The relative potency of ten types of crude leaf extracts of $E$. camaldulensis against the mosquito larvae are shown as follows in decreasing order on the basis of LC50 value: Shade chloroform $(0.356 \mathrm{mg} / \mathrm{ml})>$ sun chloroform $(0.400 \mathrm{mg} / \mathrm{ml})>$ shade di-chloromethane $(0.411 \mathrm{mg} / \mathrm{ml})>$ sun di-chloromethane $(0.579 \mathrm{mg} / \mathrm{ml})>$ shade ethanol $(0.736 \mathrm{mg} / \mathrm{ml})>$ sun ethanol $(0.817 \mathrm{mg} / \mathrm{ml})>$ shade acetone $(1.000 \mathrm{mg} / \mathrm{ml})>$ sun acetone $(1.251 \mathrm{mg} / \mathrm{ml})>$ shade water $(1.807 \mathrm{mg} / \mathrm{ml})>$ sun water $(2.020 \mathrm{mg} / \mathrm{ml})$. Here, the effectiveness of the shade dried chloroform based leaf extracts showed highest larvicidal potency because the toxic ingredients present in the leaf powder was highly soluble in chloroform and it is assumed that in the shade dried form the volatile components completely remained in the leaf.

Both seed and leaf extracts of E. globulus against Culex pipiens display 100 and 80\% mortality at $1 \mathrm{mg} / \mathrm{ml}$ (22). The larvicidal activities of ethanolic and aqueous crude extracts of Dracaena loureiri fruits against the 3rd instar larvae of Ae. aegypti after $24 \mathrm{hrs}$ exposure the ethanolic extract of endocarp showed the highest activity with $\mathrm{LC}_{50}$ value of 0.084 $\mathrm{mg} / \mathrm{ml}^{(23)}$, while in this study ethanolic and aqueous crude extracts E. camaldulensis shows 
$50 \%$ mortality with $\mathrm{LC}_{50}$ value of $0.817,0.736 \mathrm{mg} / \mathrm{ml}$ (sun and shade dried leaf) and 2.020, $1.807 \mathrm{mg} / \mathrm{ml}$ (sun and shade dried leaf), respectively.

Table 4. Larvicidal efficacy of crude leaf extracts of E. camaldulensis against 3rd instar larvae of Cx. quinquefasciatus.

\begin{tabular}{|c|c|c|c|c|c|}
\hline \multirow{2}{*}{$\begin{array}{l}\text { Different solvent based } \\
\text { leaf extracts of } E \text {. } \\
\text { camaldulensis }\end{array}$} & \multicolumn{2}{|c|}{ LC 50 values } & \multicolumn{2}{|c|}{$\begin{array}{l}95 \% \text { confidence limit for } \\
\text { concentrations }(\mathrm{mg} / \mathrm{ml})\end{array}$} & \multirow{2}{*}{$\begin{array}{l}\text { ANOVA } \\
\text { (Significant } \\
\text { value) }\end{array}$} \\
\hline & $\mathrm{LC}_{50}$ & $\mathrm{LC}_{90}$ & $\begin{array}{c}\mathrm{LC}_{50} \\
\text { (LCL-UCL) }\end{array}$ & $\begin{array}{c}\mathrm{LC}_{90} \\
(\mathrm{LCL}-\mathrm{UCL}) \\
\end{array}$ & \\
\hline $\begin{array}{l}\text { Chloroform } \\
\text { (Sun dried) }\end{array}$ & 0.400 & 1.363 & $0.334-0.459$ & $1.125-1.805$ & 0.000 \\
\hline $\begin{array}{l}\text { Chloroform } \\
\text { (Shade dried) }\end{array}$ & 0.356 & 1.069 & $0.264-0.433$ & $0.853-1.559$ & 0.000 \\
\hline $\begin{array}{l}\text { Di-chloromethane } \\
\text { (Sun dried) }\end{array}$ & 0.579 & 2.694 & $0.512-0.648$ & $2.074-3.958$ & 0.000 \\
\hline $\begin{array}{l}\text { Di-chloromethane } \\
\text { (Shade dried) }\end{array}$ & 0.411 & 1.346 & $0.341-0.473$ & $1.105-1.805$ & 0.000 \\
\hline Ethanol (Sun dried) & 0.817 & 2.247 & $0.734-0.894$ & $2.003-2.596$ & 0.000 \\
\hline Ethanol (Shade dried) & 0.736 & 1.801 & $0.664-0.804$ & $1.634-2.027$ & 0.000 \\
\hline Acetone( Sun dried) & 1.251 & 5.035 & $1.124-1.386$ & $3.994-7.008$ & 0.000 \\
\hline Acetone (Shade dried) & 1.000 & 3.486 & $0.894-1.102$ & $2.924-4.367$ & 0.000 \\
\hline Water (Sun dried) & 2.020 & 5.432 & $1.879-2.182$ & $4.521-7.095$ & 0.000 \\
\hline Water (Shade dried) & 1.807 & 4.467 & $1.686-1.932$ & $3.858-5.484$ & 0.000 \\
\hline
\end{tabular}

In another study, showed the larvicidal activity of the chloroform extracts of the seeds of Argemone maxicana against $C x$. quinquefasciatus after $24 \mathrm{hrs}$ exposure the $\mathrm{LC}_{50}$ value was $0.72 \mathrm{mg} / \mathrm{ml}^{(24)}$ but in present study, the chloroform extracts of the leaves of E. camaldulensis against the same species of the mosquito and same exposure time the $\mathrm{LC}_{50}$ value was 0.400 and $0.356 \mathrm{mg} / \mathrm{ml}$ (sun and shade dried leaf, respectively).

In comparison of the results of the earlier experiments, it is found that the results of the present study is quite different, many reasons are responsible behind this such as the difference may be due to the different geographical condition, different plant parts, different stages of the larvae, differences in tested organism, different exposure time, temperature and humidity difference, solvents solubilize by extracts etc.

After considering the above condition, it can be concluded that the leaf extracts of E. camaldulensis has been found to be an excellent larvicidal efficacy against the 3rd instar larvae of $C x$. quinquefasciatus. Various synthetic insecticides which are used to control mosquito have harmful effect on human health. In addition, nowadays mosquitoes are developing resistance to these chemicals (25). Present findings suggested that the use of $E$. 
camaldulensis leaf extracts may be a highly effective approach for mosquito management program as an alternative method for replacement of some chemical compounds on the environment. It may be cheaper, biodegradable and can be used easily without facing hazardous effects. It is expected that the active component which have insecticidal properties in the leaf of E. camaldulensis can be isolated and used as insecticide against the larvae of $C x$. quinquefasciatus mosquito.

\section{Acknowledgements}

The authors gratefully acknowledge the supports provided by the Department of Zoology, University of Dhaka.

\section{References}

1. Haque U, HJ Overgaard, AC Clements, DE Norris, N Islam and J Karim 2014. Malaria burden and control in Bangladesh and prospects for elimination: an epidemiological and economic assessment. Lancet Glob Health 2: 98-105.

2. Hafiz I, P Graves, R Haq, MS Flora and HL Kelly 2015. Clinical case estimates of lymphatic filariasis in an endemic district of Bangladesh after a decade of mass drug administration. T Roy Soc Trop Med Hyg. 109: 700-709.

3. World Health Organization 2014. Bibliography of scientific publications on vector-borne diseases from WHO south-east Asia region 2009-2013. New Delhi: World Health Organization.

4. Irish SR, MA Hasan, SA Mohammad and EH Ralph 2016. A review of the mosquito species (Diptera:Culicidae) of Bangladesh. Parasites \& Vectors 559.

5. Khan HR, M Mujahid, T Akter, MR Karim and MS Farid 2014. Diversity of the mosquito and their seasonal fluctuation in two wards of Dhaka city. Dhaka Univ. J. Biol. Sci. 23(1): 17-26.

6. Mabey, R 1997. Plant with a purpose, 2nd edition, New Hollywood California, pp. 53-60.

7. Maciel MV, SM Morais, CML Bevilaqua, RA Silva, RS Barros, RN Sousa, LC Sousa, ES Brito and MA Souza-Neto 2010. Chemical composition of Eucalyptus spp. essential oils and their insecticidal effects on Lutzomyia longipalpis. Veterinary Parasitology 167: 1-7.

8. Ulukanli Z, M Cenet, B Ozturk and SC Demirci 2015. Phytotoxic antimicrobial and insecticidal activities of Vitex agnus-castus'essential oil from East Mediterranean Region. Journal of Essential Oil-Bearing Plants 18(6): 1500-1507.

9. Kocak B and C Darici 2016. Priming effects of leaves of Laurus nobilis L. and 1, 8-cineole on carbon mineralization. Chilean Journal of Agricultural Research 76: 100-104.

10. Duke JA 2004. Dr. Duke's Phytochemical and Ethnobotanical databases. Available from: http://www.ars-grin.gov/duke.

11. Van VSF and AM Viljoen 2007. Antimicrobial activity of limonene enantiomers and 1,8cineole alone and in combination. Flavour and Fragrance Journal 22: 540-544.

12. Anupam G, C Nandita and C Goutan 2011. Review article, Plant extracts as a potential mosquito larvicides. Indian Journal of Medical Research 135: 581-598. 
13. Cheng SS, CG Huang, YJ Chen, JJ Yu, WJ Chen and ST Chang 2009. Chemical compositions and larvicidal activities of leaf essential oils from two Eucalyptus species. Bioresour. Technol. 100: 452-456.

14. Brito JP, JEM Oliveira and SA Bortoli 2006. Toxicidade de ó leos essenciais de Eucalyptus spp. sobre Callosobruchus maculatus (Fabr., 1775) (Coleoptera: Bruchidae). Rev. Biol. Sci. da Terra. 6: 96-103.

15. Yaghoobi-Ershadi MR, AA Akhavan, E Jahanifard, H Vantandoost, GH Amin, L Moosavi, ARZ Ramazani, H Abdoli and MH Arandian 2006. Repellency effect of Myrtle essential oil and DEET against Phlebotomus papatasi, under laboratory conditions. Iran. J. Publ. Health 35: $7-13$

16. Nathan SS. 2007. The use of Eucalyptus tereticornis Sm. (Myrtaceae) oil (leaf extract) as a natural larvicidal agent against the malaria vector Anopheles stephensi Liston (Diptera: Culicidae). Bioresource Tec. 98 (9):1856-60.

17. Trigg JK. 1996. Valuation of a Eucalyptus-based repellent against Anopheles spp. in Tanzania. J Am. Mosq. Control Assoc. 12: 243-6.

18. Bram AR 1967. Contributions to the mosquito fauna to the Southeast Asia-11. The genus Culex in Thailand (Diptera : Culicidae). Am. Ent. Inst. 2(1): 192-201.

19. Nour $\mathrm{AH}^{1}$, J Sandanasamy and $\mathrm{AH}^{2}$ Nour 2012. Larvicidal activity of extracts from different parts of neem (Azadirachta indica) against the mosquito larvae of Aedes aegypti. Scientific Research and Essays 7(31): 2810-2815.

20. Dua VK, AC Pandey, K Raghavendra, A Gupta, T Sharma and AP Dash 2009. Larvicidal activity of neem oil (Azadirachta indica) formulations against mosquitoes. Malaria J. 8(1): 124.

21. Abbott WS 1925. A method of computing the effectiveness of insecticides. J. Econ. Entomol. 18(2): 267-269.

22. Elbana SM 2006. Larvicidal effects of Eucalyptus extract on the larvae of Culex pipiens mosquito. Int. J. Agri. Biol. 8(6): 896.

23. Thongwat D, L Supaporn, P Urat and B Nophawan 2017. Larvicidal activity of endocarp and seed crude extracts of Dracaena loureiri Gagnep against Aedes aegypti (L.) mosquito. Asian Pac. J. Trop. Biomed. 7(3): 222-226.

24. Ali H, I Sadequl, S Shabnam, BR Shahina, N Meherum and I Nurul 2017. Lethal action of Argemone mexicana L. extracts against Culex quinquefasciatus (Say) larvae and Tribolium castaneum (Hbst.) adults. Journal of Pharmacognosy and Phytochemistry 6(1): 438-441.

25. World Health Organization 1992. Vector resistance to pesticides. Fifteenth report of the WHO expert committee on vector biology and control. WHO. Tech .Rep. Ser. 62: 818. 